\title{
Extreme temperatures and emergency department admissions for childhood asthma in Brisbane, Australia
}

\author{
Zhiwei $\mathrm{Xu}_{1}{ }^{1}$ Cunrui Huang, ${ }^{2}$ Wenbiao Hu${ }^{3}$ Lyle R Turner, ${ }^{1}$ Hong Su, ${ }^{4}$ Shilu Tong ${ }^{1}$
}

\begin{abstract}
${ }^{1}$ School of Public Health and Social Work and Institute of Health and Biomedical Innovation, Queensland University of Technology, Brisbane, Queensland, Australia

${ }^{2}$ Centre for Environment and Population Health, School of Environment, Griffith University, Brisbane, Queensland, Australia ${ }^{3}$ School of Population Health, University of Queensland, Brisbane, Queensland, Australia

${ }^{4}$ Department of Epidemiology and Health Statistics, School of Public Health, Anhui Medical University, Hefei, Anhui, China
\end{abstract}

\section{Correspondence to}

Dr Shilu Tong, School of Public Health and Social Work and Institute of Health and Biomedical Innovation, Queensland University of Technology, Kelvin Grove, Brisbane, QLD, 4059 , Australia; s.tong@qut.edu.au

Received 27 March 2013 Revised 26 June 2013

Accepted 11 July 2013 Published Online First 24 July 2013

To cite: $X u Z$, Huang $C$, $\mathrm{Hu}$ W, et al. Occup Environ Med 2013;70:730-735.

\begin{abstract}
Objectives To examine the effect of extreme temperatures on emergency department admissions (EDAs) for childhood asthma.

Methods An ecological design was used in this study. A Poisson linear regression model combined with a distributed lag non-linear model was used to quantify the effect of temperature on EDAs for asthma among children aged 0-14 years in Brisbane, Australia, during January 2003-December 2009, while controlling for air pollution, relative humidity, day of the week, season and long-term trends. The model residuals were checked to identify whether there was an added effect due to heat waves or cold spells.
\end{abstract}

Results There were 13324 EDAs for childhood asthma during the study period. Both hot and cold temperatures were associated with increases in EDAs for childhood asthma, and their effects both appeared to be acute. An added effect of heat waves on EDAs for childhood asthma was observed, but no added effect of cold spells was found. Male children and children aged $0-4$ years were most vulnerable to heat effects, while children aged 10-14 years were most vulnerable to cold effects. Conclusions Both hot and cold temperatures seemed to affect EDAs for childhood asthma. As climate change continues, children aged $0-4$ years are at particular risk for asthma.

\section{INTRODUCTION}

Asthma is one of the most frequent chronic childhood illnesses worldwide. ${ }^{1}$ It was the most common of the five most frequently reported longterm conditions among Australian children aged 0-14 years in 2007-2008, ${ }^{2}$ and will continue to be a major cause of disease burden in Australia over the next two decades. ${ }^{2}$ Currently, there is no cure for asthma, so it is particularly important to identify potential risk factors and vulnerable subgroups, in order that targeted control and prevention strategies can be developed. Although the aetiology of asthma has not been fully elucidated, there is evidence that environmental factors may trigger asthma attacks. $^{3-5}$ Previous studies have found an inverse association between monthly ambient temperatures and hospital admissions for asthma in different regions. ${ }^{6} 7$ However, little is known about the impact of extreme temperatures on childhood asthma.

Persistent extreme temperatures (ie, heat waves and cold spells) have been found to adversely affect mortality and morbidity. ${ }^{8-10}$ Some studies have

\section{What this paper adds}

- It has been reported that cold spells are associated with childhood asthma.

- However, there is little information on whether hot temperatures affect the incidence of childhood asthma, and no study has examined whether the increased risk of childhood asthma during extreme temperature periods is due to the main effect of daily temperature fluctuations and/or the added effect of persistent extreme temperatures.

- In this study, we found both hot and cold temperatures were associated with increases in emergency department admissions for childhood asthma, and both of their effects appeared to be acute; there was an added effect of heat waves on childhood asthma.

- Male children and children aged 0-4 years were more vulnerable to heat effects, while children aged 10-14 years were more vulnerable to cold effects.

- These findings may shed some light on the possible future impact of climate change on childhood asthma.

found that the effects of persistent extreme temperatures on human health are due to the independent effects of ambient daily temperature (main effect) and of sustained periods of heat and cold (added effect). ${ }^{8} 11{ }^{12}$ Recently, Guo et $a l^{13}$ found a significant relationship between cold spells and paediatric outpatient visits for asthma in Shanghai, China. However, to the best of our knowledge, to date, no studies have specifically examined whether the increased risk of childhood asthma during extreme temperature periods is due to the main effect of daily temperature fluctuations and/or the added effect of persistent extreme temperatures.

There is a need to systematically explore the impacts of daily extreme temperatures and of consecutive days of extreme temperatures on childhood asthma occurrence. This study attempted to answer three questions: (1) what is the relationship between extreme temperatures and emergency department admissions (EDAs) for childhood asthma? (2) is there any added effect due to heat waves and cold spells? and (3) which subgroups are most vulnerable to the effects of extreme temperatures? 


\section{MATERIALS AND METHODS}

\section{Study design}

An ecological design was used in this study to assess the impact of extreme temperatures on daily EDAs for childhood asthma.

\section{Data collection}

Brisbane is the state capital of Queensland, located on the east coast of Australia. It has a subtropical climate, with mild winters and hot summers. Children aged $0-14$ years account for $18 \%$ of the residential population in Brisbane. ${ }^{14}$

Electronic medical records containing EDA data for Brisbane from 1 January 2003 to 31 December 2009 were retrieved from Queensland Health. The EDA data were classified according to the International Classification of Diseases, 10th revision (ICD-10) and those coded as asthma (J45) in children aged 014 years were selected. Daily weather data for the same period, including maximum temperature, minimum temperature and relative humidity, were provided by the Australian Bureau of Meteorology. Daily mean temperature was calculated by averaging the daily maximum and minimum temperatures. Air pollution data, including daily average particular matter $\leq 10 \mu \mathrm{m}$ $\left(\mathrm{PM}_{10}, \mu \mathrm{g} / \mathrm{m}^{3}\right)$, daily average nitrogen dioxide $\left(\mathrm{NO}_{2}, \mu \mathrm{g} / \mathrm{m}^{3}\right)$ and daily average ozone $\left(\mathrm{O}_{3}, \mathrm{ppb}\right)$ levels, were obtained from the Queensland Department of Environment and Heritage Protection.

\section{Heat wave and cold spell definitions}

To date, there are no standard definitions for either heat waves or cold spells, mainly because of variations in population characteristics and individual adaptation capability. ${ }^{15}{ }^{16}$ In this study, we identified heat waves and cold spells according to temperature intensity and duration: (1) the 5th and 6th percentiles of daily mean temperature were defined as the cold threshold, and the 95 th and 96 th percentiles of the daily mean temperature as the heat threshold; and (2) a minimum of 2-4 consecutive days with temperatures below the cold threshold or above the heat threshold were required.

\section{Data analysis}

Stage I: estimating the main temperature effects

A Poisson generalised linear regression model combined with a distributed lag non-linear model (DLNM) was used to estimate the association between temperature and EDAs for childhood asthma. As the relationship between temperature and morbidity has been reported to be non-linear, ${ }^{17}$ a natural cubic spline with 5 degrees of freedom (df) was used to capture the non-linear temperature effects. Previous studies have reported that there is a lagged effect of temperature on morbidity, ${ }^{18}{ }^{19}$ so we plotted a three-dimensional figure of temperature effect on EDAs for childhood asthma, which simultaneously incorporated nonlinear exposure-response relationships and lagged effects.

$$
\begin{aligned}
\mathrm{Y}_{\mathrm{t}} \sim \text { Poisson }\left(\mu_{\mathrm{t}}\right) & \\
\log \left(\mu_{\mathrm{t}}\right)= & \alpha+\beta \mathrm{T}_{\mathrm{t}, 1}+\mathrm{ns}\left(\mathrm{RH}_{\mathrm{t}}, 4\right)+\mathrm{ns}\left(\mathrm{PM}_{10 \mathrm{t}}, 4\right)+\mathrm{ns}\left(\mathrm{O}_{3 \mathrm{t}}, 4\right) \\
& +\mathrm{ns}\left(\mathrm{NO}_{2 \mathrm{t}}, 4\right)+\mathrm{ns}\left(\mathrm{Time}_{\mathrm{t}}, 7\right)+\eta \mathrm{DOW}_{\mathrm{t}}
\end{aligned}
$$

where $t$ is the day of the observation, $Y_{t}$ is the observed daily EDAs for childhood asthma on day $t, \alpha$ is the model intercept, $\mathrm{T}_{\mathrm{t}, \mathrm{l}}$ is a matrix obtained by applying the DLNM to temperature, $\beta$ is the vector of coefficients for $T_{t, 1}$ and 1 is the lag days, ns $\left(\mathrm{RH}_{\mathrm{t}}, 4\right)$ is a natural cubic spline with $4 \mathrm{df}$ for relative humidity, $\mathrm{ns}\left(\mathrm{PM}_{10 \mathrm{t}}, 4\right)$ is a natural cubic spline with $4 \mathrm{df}$ for $\mathrm{PM}_{10}$, ns
$\left(\mathrm{O}_{3 \mathrm{t}}, 4\right)$ is a natural cubic spline with $4 \mathrm{df}$ for $\mathrm{O}_{3}, \mathrm{~ns}\left(\mathrm{NO}_{2 \mathrm{t}}, 4\right)$ is a natural cubic spline with $4 \mathrm{df}$ for $\mathrm{NO}_{2}$, ns (Time, , 7 ) is a natural cubic spline with $7 \mathrm{df}$ for seasonality and long-term trend, and $\mathrm{DOW}_{\mathrm{t}}$ is the categorical day of the week with a reference day of Sunday.

After all the other parameters were confirmed, we checked the temperature-asthma plot and chose the reference temperature by visual inspection. We evaluated the relative risk of EDAs for childhood asthma associated with high temperature $\left(26.5^{\circ} \mathrm{C}\right.$, 95th percentile of mean temperature) relative to the reference temperature (chosen to be $24.0^{\circ} \mathrm{C}$ ). Similarly, we evaluated the relative risk of EDAs for childhood asthma associated with low temperature $\left(13.8^{\circ} \mathrm{C}, 5\right.$ th percentile of mean temperature) relative to the reference temperature $\left(24.0^{\circ} \mathrm{C}\right)$.

\section{Stage II: examining the added effects of heat waves and cold spells}

Previous studies have documented that sustained periods of heat and cold could produce an added effect on mortality independent of daily temperature effect. ${ }^{8} 1112$ We analysed the residuals of the stage I model to examine the potential added effects of heat waves and cold spells. At stage II, we estimated the added effects of heat waves and cold spells after removing the main effects of temperature. We assumed a maximum lag of 21 days for the delayed effects of heat waves and cold spells. EDAs for childhood asthma on extreme temperature days were compared with those on non-extreme temperature days.

$$
\log \left(\mu_{\mathrm{t}}\right)=\log \left(\mu_{\mathrm{t} 1}\right)+\beta_{1} \mathrm{C}_{\mathrm{t}, 1}+\beta_{2} \mathrm{H}_{\mathrm{t}, 1} \quad \mathrm{t}=1,2, \ldots, \mathrm{n}
$$

where $\log \left(\mu_{t 1}\right)$ is the estimated EDAs for childhood asthma counts on day $t$ from the stage $I$ model, $\mathrm{C}_{t, 1}$ is a matrix applying DLNM to cold spells, and $\mathrm{H}_{\mathrm{t}, \mathrm{l}}$ is a matrix applying DLNM to heat waves.

All data analysis was conducted using the $\mathrm{R}$ statistical environment (V.2.15) with the 'dlnm' package used to fit the regression model. ${ }^{20}$ The sensitivity analysis was performed by changing the degrees of freedom for time, temperature and humidity, as well as the definitions of hot and cold temperatures.

\section{RESULTS}

\section{Characteristics of weather variables, air pollutants and daily EDAs for childhood asthma}

The summary statistics for weather variables, air pollutants and EDAs for age- and gender-specific childhood asthma are given in table 1 . The average mean temperature and relative humidity were $20.6^{\circ} \mathrm{C}$ and $57.3 \%$, respectively. The average values for $\mathrm{O}_{3}, \mathrm{PM}_{10}$ and $\mathrm{NO}_{2}$ were $12.6 \mathrm{ppb}$ (range: 1.7-31.6), $16.0 \mu \mathrm{g} /$ $\mathrm{m}^{3}(4.4-355.2)$ and $7.0 \mu \mathrm{g} / \mathrm{m}^{3}(3.8-25.3)$, respectively. There were 13324 EDAs for childhood asthma in Brisbane over the study period. Among these EDAs, 8230 were males and 5094 were females, 8643 were children aged 0-4 years, 3398 were children aged 5-9 years and 1283 were children aged 1014 years. The mean daily number of EDAs for asthma among children aged $0-4$ years (3.4) was greater than among children aged 5-9 years (1.3) and 10-14 years (0.5).

Figure 1 illustrates the daily distribution of EDAs for childhood asthma in Brisbane over the study period, indicating a seasonal pattern. Figure 2, which shows the monthly distribution of childhood asthma, reveals that childhood asthma was more prevalent in the months of February, May, June and July than in other months in Brisbane. 
Table 1 Summary statistics for daily climatic variables, air pollutants and mean daily number of emergency department admissions for childhood asthma in Brisbane, Australia, 2003-2009

\begin{tabular}{|c|c|c|c|c|c|c|c|}
\hline \multirow[b]{2}{*}{ Variables } & \multirow[b]{2}{*}{ Mean } & \multirow[b]{2}{*}{ SD } & \multirow[b]{2}{*}{ Min } & \multicolumn{3}{|c|}{ Percentile } & \multirow[b]{2}{*}{ Max } \\
\hline & & & & 25 & 50 & 75 & \\
\hline Mean temperature $\left({ }^{\circ} \mathrm{C}\right)$ & 20.6 & 4.1 & 9.0 & 17.3 & 20.9 & 23.8 & 34.2 \\
\hline Relative humidity (\%) & 57.3 & 16.0 & 5.0 & 49.0 & 58.0 & 67.0 & 98.0 \\
\hline $\mathrm{O}_{3}(\mathrm{ppb})$ & 12.6 & 3.9 & 1.7 & 9.9 & 12.3 & 14.9 & 31.6 \\
\hline $\mathrm{PM}_{10}\left(\mu \mathrm{g} / \mathrm{m}^{3}\right)$ & 16.0 & 10.1 & 4.4 & 11.7 & 14.5 & 17.9 & 355.2 \\
\hline $\mathrm{NO}_{2}\left(\mu \mathrm{g} / \mathrm{m}^{3}\right)$ & 7.0 & 4.2 & 0 & 3.8 & 6.0 & 9.7 & 25.3 \\
\hline Asthma & 5.2 & 3.3 & 0 & 3 & 5 & 7 & 23 \\
\hline Aged $0-4$ years asthma & 3.4 & 2.4 & 0 & 2 & 3 & 5 & 15 \\
\hline Aged 5-9 years asthma & 1.3 & 1.4 & 0 & 0 & 1 & 2 & 9 \\
\hline Aged $10-14$ years asthma & 0.5 & 0.8 & 0 & 0 & 0 & 1 & 6 \\
\hline Male asthma & 3.2 & 2.4 & 0 & 1 & 3 & 5 & 15 \\
\hline Female asthma & 2.0 & 1.7 & 0 & 1 & 2 & 3 & 11 \\
\hline
\end{tabular}

\section{Association between temperature and EDAs for childhood asthma}

Figure 3 shows the exposure-response relationship between daily mean temperature and EDAs for childhood asthma for different lag periods. It clearly shows that both cold and hot temperature had significant effects on EDAs for childhood asthma, and their effects occurred on the same day as exposure. Extremely high temperatures had a particularly large effect on EDAs for childhood asthma, although the effect of extremely high temperatures was found in a region with few data points. Figure 3 also shows that, for lag 0 , the risks of cold temperature decreased slightly when the temperature was below the 5 th percentile.

Table 2 shows the effects of high and cold temperatures at several lags, revealing that male children and children aged $0-4$ years were particularly sensitive to hot temperature, and children aged 10-14 years were particularly sensitive to cold effect. The fact that hot temperatures had a greater effect than cold temperatures is indicated in figure 3 but appears not to be reflected in table 2 . This is mainly because the greatest effect of heat is observed far above the 95th percentile, which is what is reported in table 2. Further, in table 2, the magnitude of hot and cold temperature effects on childhood asthma appeared to be greatest at lag 0-21 days because of the cumulative effect estimate we reported. In fact, the shortest lags are the most important and the effects of both hot and cold temperatures were acute.

\section{Added effects of heat waves and cold spells}

Table 3 shows the daily excess EDAs for childhood asthma on heat wave days and cold spell days as opposed to non-heat wave days and non-cold spell days. Using a heat wave definition of 2 days with the temperature over the 95 th or 96 th percentile, we found there was not a significant increase in EDAs for childhood asthma in heat waves. However, using a heat wave definition of 3 days with the temperature over the 95 th or 96 th percentile, we found there were significant increases in EDAs for childhood asthma in heat waves. There was no significant increase in EDAs for childhood asthma during cold spells.

\section{Sensitivity analysis results}

To conduct the sensitivity analysis, we changed the degrees of freedom (8-15 per year) for time to control for season. We also altered the degrees of freedom (5-7) for temperature and humidity. Further, we changed the definitions of high temperature $\left(27.8^{\circ} \mathrm{C}, 99\right.$ th percentile of mean temperature) and cold temperature $\left(11.9^{\circ} \mathrm{C}\right.$, 1 st percentile of mean temperature) for use in comparison with the reference temperature $\left(24^{\circ} \mathrm{C}\right)$ and estimation of the relative risk of EDAs for childhood asthma. The results were similar (results not shown).
Figure 1 Time-series plot of the daily distribution of emergency department admissions (EDAs) for childhood asthma.

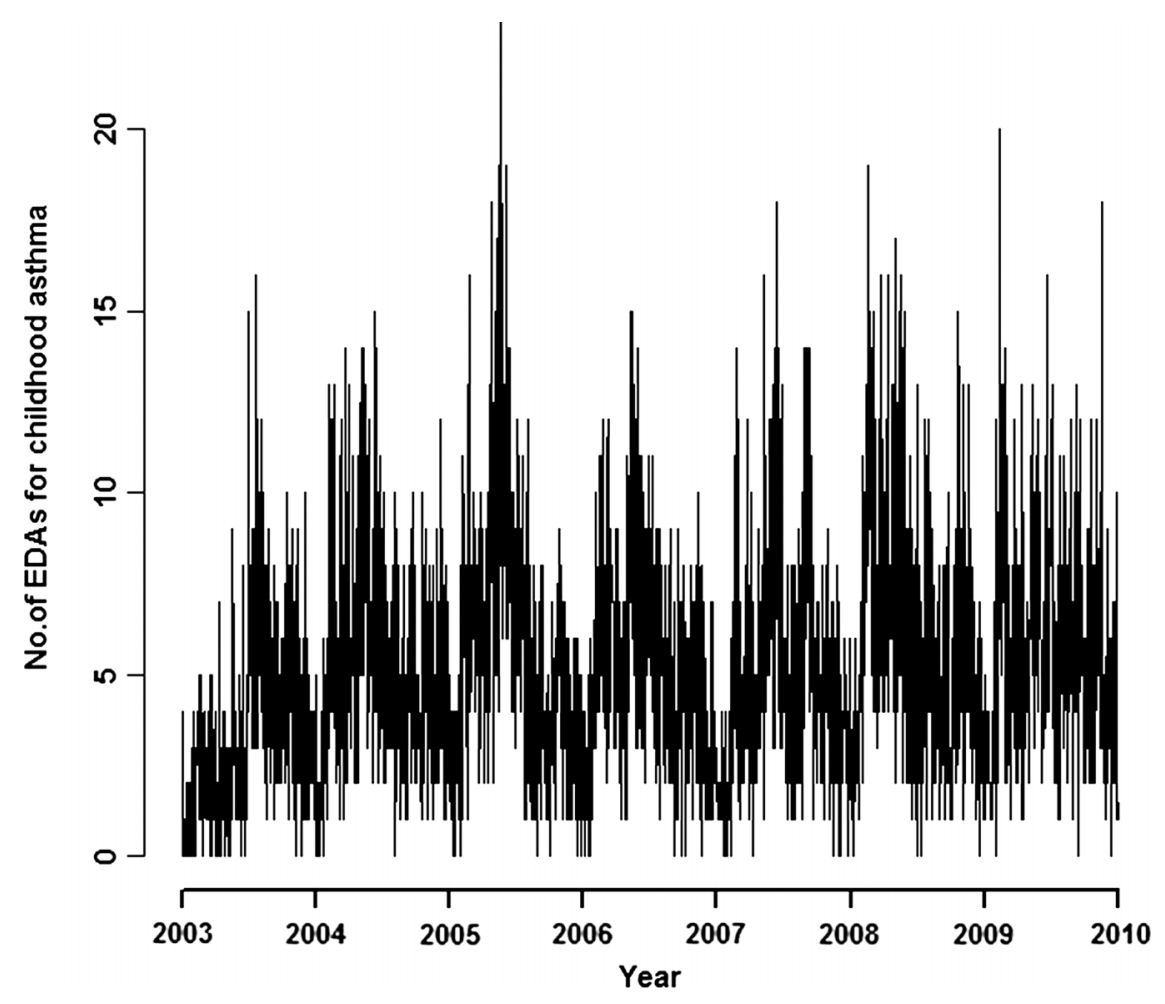


Figure 2 Box plot of the monthly distribution of emergency department admissions (EDAs) for childhood asthma.

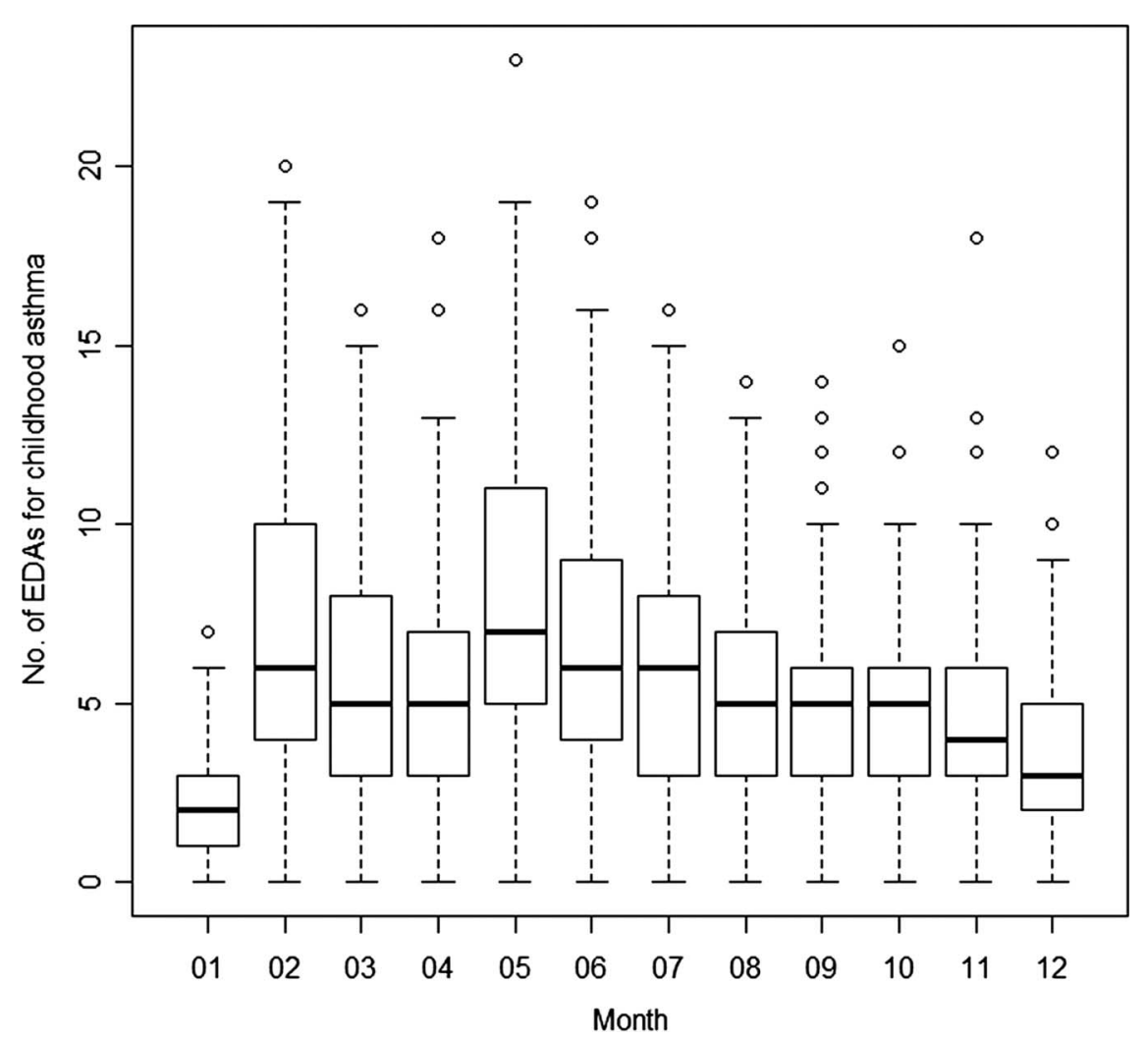

\section{DISCUSSION}

In recent years, the public health literature has increasingly recognised that extreme temperatures have a significant health impact on paediatric respiratory diseases. ${ }^{21}$ This study assessed the effects of extreme temperatures on EDAs for childhood asthma, and explored the added effects of heat waves and cold

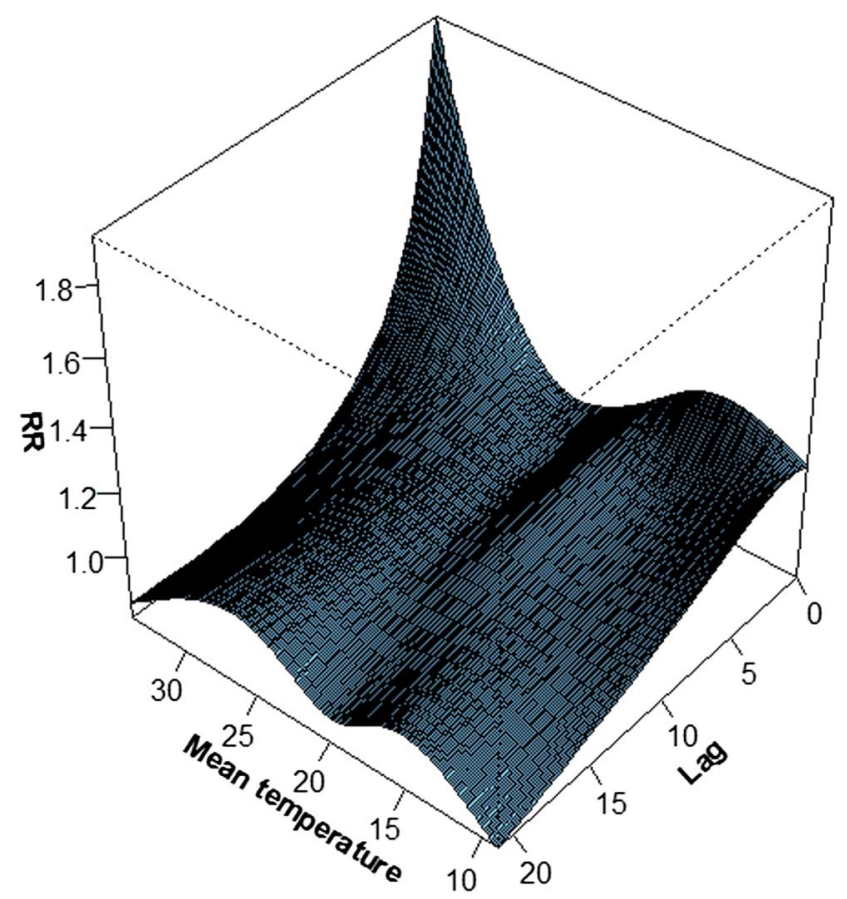

Figure 3 Three-dimensional graph of daily temperature effects on emergency department admissions (EDAs) for childhood asthma. Access the article online to view this figure in colour. spells. The results suggest that both hot and cold temperatures were significantly associated with increases in EDAs for childhood asthma in Brisbane. Lagged effects of heat and cold on EDAs for childhood asthma were observed. Male children and children aged $0-4$ years were particularly vulnerable to heat, while children aged 10-14 years were more sensitive to cold. Statistically significant added effects of heat waves were observed, with seven to eight EDAs for childhood asthma per day depending on the severity of the heat wave, although the findings were mainly based on only 1 or 2 days of data.

Temperature can directly influence childhood asthma by affecting inflammation pathways or airway hyper-responsiveness. ${ }^{22}$ In addition, temperature may also indirectly affect asthma triggers, such as viral infections, ${ }^{23}$ bacterial activity, ${ }^{24}$ the growth of indoor allergens ${ }^{25}$ and time spent outdoors. This study found cold temperature was significantly associated with an increase in EDAs for asthma, which corresponds to previous findings from China, Canada and the USA. ${ }^{13} 2226$ The effect of cold temperature on childhood asthma may be due to the fact that low temperatures facilitate bacterial survival in water droplets ${ }^{24}$ and encourage cross-infection from crowding indoors. The literature has documented that abrupt cooling of air enhances inflammation and thereby causes airway narrowing and exacerbates asthma. ${ }^{27}$ To date, however, very few studies have found adverse effects of high temperature on childhood asthma. ${ }^{28}$ Higher temperatures can enhance the growth of indoor allergens, such as moulds, mites and cockroaches, ${ }^{21}$ which play a role in the occurrence of asthma. Differing pollution patterns in summer and winter indicate that levels of pollutants such as $\mathrm{O}_{3}$ and $\mathrm{PM}_{10}$ may be higher in hot weather. ${ }^{29}$ Direct and interaction effects of pollutants on asthma are therefore more likely to be experienced in summer periods, particularly as children often engage in outdoor activities. It is very important to determine how high temperature influences asthma, because the burden of asthma is expected to increase in many developed countries ${ }^{30}$ and the 
Table 2 The effects of hot and cold temperatures on emergency department admissions for childhood asthma, with the 95th percentile $\left(26.5^{\circ} \mathrm{C}\right)$ and the 5 th percentile $\left(13.8^{\circ} \mathrm{C}\right)$ of temperature relative to the reference temperature $\left(24^{\circ} \mathrm{C}\right)$

\begin{tabular}{|c|c|c|c|c|c|c|}
\hline \multirow[b]{2}{*}{ Children category } & \multicolumn{3}{|c|}{ Heat effect relative risk $(95 \% \mathrm{CI})$} & \multicolumn{3}{|c|}{ Cold effect relative risk $(95 \% \mathrm{Cl})$} \\
\hline & Lag 0-1 days & Lag 0-13 days & Lag 0-21 days & Lag 0-1 days & Lag 0-13 days & Lag 0-21 days \\
\hline All ages & $1.12(1.02 \text { to } 1.22)^{*}$ & $1.53(1.19 \text { to } 1.95)^{*}$ & $1.80(1.27 \text { to } 2.57)^{*}$ & $1.45(1.20 \text { to } 1.74)^{*}$ & $1.69(1.12 \text { to } 2.55)^{*}$ & 1.25 (0.80 to 1.95$)$ \\
\hline $0-4$ years & $1.17(1.06 \text { to } 1.29)^{*}$ & $1.61(1.22 \text { to } 2.14)^{*}$ & $1.92(1.29 \text { to } 2.86)^{*}$ & $1.27(1.03 \text { to } 1.58)^{*}$ & $1.56(0.97$ to 2.52$)$ & 1.06 (0.63 to 1.77$)$ \\
\hline $5-9$ years & $0.93(0.79$ to 1.10$)$ & $1.13(0.72$ to 1.76$)$ & 1.27 (0.67 to 2.38$)$ & $1.67(1.20 \text { to } 2.31)^{*}$ & $1.53(0.74$ to 3.15$)$ & 1.26 (0.58 to 2.73$)$ \\
\hline $10-14$ years & 1.12 (0.89 to 1.42$)$ & 1.61 (0.84 to 3.11$)$ & $1.67(0.67$ to 4.27$)$ & $1.83(1.38 \text { to } 2.58)^{*}$ & $1.96(1.03 \text { to } 3.50)^{*}$ & 1.41 (0.77 to 3.62$)$ \\
\hline Male & $1.13(1.02 \text { to } 1.25)^{*}$ & $1.63(1.22 \text { to } 2.20)^{*}$ & $2.11(1.38 \text { to } 3.21)^{*}$ & $1.30(1.04 \text { to } 1.62)^{*}$ & $1.69(1.03 \text { to } 2.78)^{*}$ & $1.24(0.73$ to 2.12$)$ \\
\hline Female & $1.08(0.95$ to 1.23$)$ & 1.37 (0.97 to 1.96$)$ & 1.42 (0.86 to 2.35$)$ & $1.73(1.32 \text { to } 2.26)^{*}$ & 1.74 (0.97 to 3.14$)$ & 1.29 (0.68 to 2.44$)$ \\
\hline
\end{tabular}

average global surface temperature is projected to rise over the coming decades. ${ }^{31}$

Understanding the lag pattern of heat and cold effects is essential for the policy makers and community leaders who develop response plans for periods of extreme temperatures. Interestingly, in this study we found that both heat and cold had acute effects. Previous studies investigating the effects of extreme temperatures on morbidity found that cold effects are not acute and last longer than heat effects. ${ }^{32}$ This inconsistency can be partially explained by the different mechanisms of cold effects on asthma. The temperature of exhaled breath has been found to be a biomarker for asthma ${ }^{33}$ and may cause acute effects in children on cold days. Cold temperature can produce robust increases in intracellular $\mathrm{Ca}^{2+}$ levels, but can also enhance expression of MUC5AC mRNA and intracellular and secreted MUC5AC protein, which activates transient receptor potential melastatin 8 (TRPM8), ${ }^{34}$ a trigger for childhood asthma.

In line with other research in the USA, England and Australia, ${ }^{6}{ }^{35-38}$ we found that children aged $0-4$ years in this study were more vulnerable to heat effects, which may be partly attributed to less self-care ability and under-developed thermoregulation capacity. ${ }^{21}$ Children aged $10-14$ years may play outdoors more often than younger children, which may increase their exposures to cold temperatures. In young females, menarche usually occurs between the ages of 10 and $14,{ }^{39}$ and the concomitant increase in ovarian hormones might affect thermoregulation, ${ }^{40}$ making these children vulnerable to extremely cold temperatures.

The results of this study suggest that there was a significant added effect of heat waves on EDAs for childhood asthma when heat wave was defined as an episode with extreme heat for more than 3 consecutive days. As climate change continues, the frequency, intensity, extent and duration of heat waves are expected to increase, ${ }^{41}$ which might increase the burden of childhood asthma in the coming decades.

No added effect of cold spells on EDAs for childhood asthma was found in this study. Further, we found the effect of cold temperatures declined slightly when the temperature was below the 5 th percentile $\left(13.8^{\circ} \mathrm{C}\right)$. This could be because children take more protective action (eg, wear more clothes) in extremely cold temperatures or after the first day's exposure to extreme cold, so they are less exposed to extreme cold during a prolonged cold spell. Additionally, Brisbane has a subtropical climate and rarely encounters really cold temperatures that last a few days. Similar findings were observed in the study by Huang et al investigating the effect of extreme temperatures on years of life lost in Brisbane, Australia. ${ }^{42}$

This study has two major strengths. To our knowledge, this is the first study to examine the main and added effect of extreme temperatures on EDAs for childhood asthma. Second, an advanced statistical method was used to quantify the temperature effect on EDAs for childhood asthma. Several limitations should also be acknowledged. First, this is a single city study, so the results must be interpreted with caution since the temperature-asthma relationship may vary geographically. However, the method used here can be employed in future studies and other geographical regions. Second, the ecological design used here may result in some biases in exposure and/or outcome measures. Third, the conclusion that heat waves had a statistically significant effect on childhood asthma is based on only 1 or 2 days of data, which introduces some uncertainty into the robustness of

Table 3 Emergency department admissions for asthma due to the added effect of heat waves and cold spells in Brisbane, Australia, 2003-2009

\begin{tabular}{|c|c|c|c|c|c|c|c|c|}
\hline \multirow[b]{2}{*}{ Number of consecutive days } & \multicolumn{4}{|l|}{ Heat waves } & \multicolumn{4}{|l|}{ Cold spells } \\
\hline & Percentile* & Dayst & Asthma & $95 \% \mathrm{Cl}$ & Percentile* & Dayst & Asthma & $95 \% \mathrm{Cl}$ \\
\hline$\geq 2$ & $\begin{array}{l}\geq 95 \text { th } \\
\geq 96 \text { th }\end{array}$ & $\begin{array}{r}13 \\
7\end{array}$ & $\begin{array}{l}1 \\
1\end{array}$ & $\begin{array}{l}-1,3 \\
-2,3\end{array}$ & $\begin{array}{l}\leq 5 \text { th } \\
\leq 4 \text { th }\end{array}$ & $\begin{array}{l}19 \\
11\end{array}$ & $\begin{array}{r}-1 \\
0\end{array}$ & $\begin{array}{l}-2,1 \\
-2,2\end{array}$ \\
\hline$\geq 3$ & $\begin{array}{l}\geq 95 \text { th } \\
\geq 96 \text { th }\end{array}$ & $\begin{array}{l}2 \\
1\end{array}$ & $\begin{array}{l}7 \\
8\end{array}$ & $\begin{array}{l}1,13 \\
1,15\end{array}$ & $\begin{array}{l}\leq 5 \text { th } \\
\leq 4 \text { th }\end{array}$ & $\begin{array}{l}4 \\
2\end{array}$ & $\begin{array}{l}-1 \\
-3\end{array}$ & $\begin{array}{l}-5,2 \\
-7,1\end{array}$ \\
\hline$\geq 4$ & $\begin{array}{l}\geq 95 \text { th } \\
\geq 96 \text { th }\end{array}$ & $\begin{array}{l}0 \\
0\end{array}$ & $\begin{array}{l}- \\
-\end{array}$ & $\begin{array}{l}- \\
-\end{array}$ & $\begin{array}{l}\leq 5 \text { th } \\
\leq 4 \text { th }\end{array}$ & $\begin{array}{l}1 \\
1\end{array}$ & $\begin{array}{l}-5 \\
-5\end{array}$ & $\begin{array}{l}-14,3 \\
-14,3\end{array}$ \\
\hline
\end{tabular}

${ }^{*}$ The threshold cut-off which we used to define heat waves and cold spells.

tThe number of heat wave and cold spell days.

¥The daily number of emergency department admissions for childhood asthma due to heat waves or cold spells. 
the findings. Fourth, the relatively fewer admissions of children aged 10-14 years may reduce the power to detect a significant association.

\section{CONCLUSIONS}

The impact of climate change on children's health has received limited attention to date. This study contributes to understanding of the effect of extreme temperatures on EDAs for childhood asthma. It found strong evidence that both heat and cold were significantly associated with an increase in EDAs for childhood asthma, and also that there is an added effect of heat waves on EDAs for asthma. Childhood asthma control and prevention strategies should focus more on male children and children aged 0-4 years on hot days, especially prolonged hot weather.

Acknowledgements We would like to thank Xiaofang Ye and Jiajia Wang for their valuable comments on an early draft.

Contributors ZX and ST designed the study. ZX analysed the data and wrote the first draft. ST, CH, WH, LRT and HS contributed to manuscript revision.

Funding ZX is funded by a China Scholarship Council Postgraduate Scholarship, a Queensland University of Technology fee waiving scholarship, and the CSIRO Climate Adaptation Flagship Collaboration Fund; ST is supported by a National Health and Medical Research Council Research Fellowship (\#553043).

\section{Competing interests None.}

Provenance and peer review Not commissioned; externally peer reviewed.

\section{REFERENCES}

1 Asher MI, Montefort S, Björkstén B, et al. Worldwide time trends in the prevalence of symptoms of asthma, allergic rhinoconjunctivitis, and eczema in childhood: ISAAC Phases One and Three repeat multicountry cross-sectional surveys. Lancet 2006;368:733-43.

2 Australian Institute of Health and Welfare (AIHW). Australian Health 2010. Canberra: AlHW, 2010.

3 Ege MJ, Mayer M, Normand AC, et al. Exposure to environmental microorganisms and childhood asthma. N Engl J Med 2011;364:701-9.

4 Ege MJ, Mayer M, Schwaiger K, et al. Environmental bacteria and childhood asthma. Allergy 2012:67:1565-71.

5 Nickmilder M, Bernard A. Ecological association between childhood asthma and availability of indoor chlorinated swimming pools in Europe. Occup Environ Med 2007;64:37-46.

6 Nastos PT, Paliatsos AG, Papadopoulos M, et al. The effect of weather variability on pediatric asthma admissions in Athens, Greece. J Asthma 2008;45:59-65.

7 Grech V, Balzan M, Asciak RP, et al. Seasonal variations in hospital admissions for asthma in Malta. J Asthma 2002;39:263-8.

8 Gasparrini A, Armstrong B. The impact of heat waves on mortality. Epidemiology 2011;22:68-73.

9 Hansen AL, Bi P, Nitschke M, et al. The effect of heatwaves on mental health in a temperate Australian city. Epidemiology 2008;19:S85.

10 Ma W, Yang C, Chu C, et al. The impact of the 2008 cold spell on mortality in Shanghai, China. Int J Biometeorol 2012;22:1-6.

11 Anderson B, Bell M. Weather-related mortality: how heat, cold, and heat waves affect mortality in the United States. Epidemiology 2009;20:205-13.

12 Hajat S, Armstrong B, Baccini M, et al. Impact of high temperatures on mortality: is there an added heat wave effect? Epidemiology 2006;17:632-8.

13 Guo $Y$, Jiang F, Peng L, et al. The association between cold spells and pediatric outpatient visits for asthma in Shanghai, China. PLOS ONE 2012;7:e42232.

14 Tong $S$, Wang XY, Guo Y. Assessing the short-term effects of heatwaves on mortality and morbidity in Brisbane, Australia: comparison of case-crossover and time series analyses. PLOS ONE 2012;7:e37500.

15 Tong S, Kan H. Heatwaves: what is in a definition? Maturitas 2011;69:5-6.

16 Tong S, Wang XY, Barnett AG. Assessment of heat-related health impacts in Brisbane, Australia: comparison of different heatwave definitions. PLOS ONE 2010;5:e12155.
17 Schwartz J, Samet JM, Patz JA. Hospital admissions for heart disease: the effects of temperature and humidity. Epidemiology 2004;15:755-61.

18 Green R, Basu R, Malig B, et al. The effect of temperature on hospital admissions in nine California counties. Int J Public Health 2010;55:113-21.

19 Lan CC, Shipley M, Marmot M, et al. Lower ambient temperature was associated with an increased risk of hospitalization for stroke and acute myocardial infarction in young women. J Clin Epidemiol 2004;57:749-57.

20 Gasparrini A, Armstrong B. Distributed lag non-linear models in R: the package dlnm. http://cran.r-project.org/web/packages/dlnm/vignettes/dlnmOverview.pdf

$21 \mathrm{Xu} Z$ Z, Etzel RA, Su H, et al. Impact of ambient temperature on children's health: a systematic review. Environ Res 2012;117:120-31.

22 Buckley JP, Richardson DB. Seasonal modification of the association between temperature and adult emergency department visits for asthma: a case-crossover study. Environ Health 2012;11:55.

23 Welliver R. The relationship of meteorological conditions to the epidemic activity of respiratory syncytial virus. Paediatr Respir Rev 2009;10(Supplement 1):6-8.

24 Handley BA, Webster AJF. Some factors affecting the airborne survival of bacteria outdoors. J App/ Microbiol 1995;79:368-78.

25 Yuksel H, TanaÇ R, Tez ECE, et al. Childhood asthma and atmospheric conditions. Pediatr Int 1996;38:606-10.

26 Villeneuve PJ, Leech J, Bourque D. Frequency of emergency room visits for childhood asthma in Ottawa, Canada: the role of weather. Int I Biometeorol 2005;50:48-56.

27 Kaminsky DA, Bates JHT, Irvin CG. Effects of cool, dry air stimulation on peripheral lung mechanics in asthma. Am J Respir Crit Care Med 2000;162:179-86.

28 Hashimoto M, Fukuda T, Shimizu T, et al. Influence of climate factors on emergency visits for childhood asthma attack. Pediatr Int 2004;46:48-52.

29 Weinmayr $\mathrm{G}$, Romeo $\mathrm{E}$, Sario MD, et al. Short-term effects of $\mathrm{PM}_{10}$ and $\mathrm{NO}_{2}$ on respiratory health among children with asthma or asthma-like symptoms: a systematic review and meta-analysis. Environ Health Perspect 2010; 118:449-57.

30 Mannino DM, Buist AS. Global burden of COPD: risk factors, prevalence, and future trends. Lancet 2007;370:765-73.

31 IPCC. Summary for policymakers. Climate change 2007: the physical science basis. Contribution of Working Group I to the Fourth Assessment Report of the Intergovernmental Panel on Climate Change. Cambridge University Press, 2007.

32 Ye X, Wolff R, Yu W, et al. Ambient temperature and morbidity: A review of epidemiological evidence. Environ Health Perspect 2012;120:19-28.

33 Piacentini GL, Bodini A, Zerman L, et al. Relationship between exhaled air temperature and exhaled nitric oxide in childhood asthma. Eur Respir J 2002;20:108-11.

34 Li M, Li Q, Yang G, et al. Cold temperature induces mucin hypersecretion from normal human bronchial epithelial cells in vitro through a transient receptor potential melastatin 8 (TRPM8)-mediated mechanism. J Allergy Clin Immunol 2011;128:626-34.e5.

35 Babin S, Burkom H, Holtry R, et al. Pediatric patient asthma-related emergency department visits and admissions in Washington, DC, from 2001-2004, and associations with air quality, socio-economic status and age group. Environ Health 2007;6:9.

36 Knowlton K, Rotkin-Ellman M, King G, et al. The 2006 California heat wave: impacts on hospitalizations and emergency department visits. Environ Health Perspect 2008;117:61-7.

37 Leonardi $G$, Hajat $S$, Kovats $R$, et al. Syndromic surveillance use to detect the early effects of heat-waves: an analysis of NHS direct data in England. Soz Praventivmed 2006;51:194-201.

38 Nitschke M, Tucker $G$, Hansen A, et al. Impact of two recent extreme heat episodes on morbidity and mortality in Adelaide, South Australia: a case-series analysis. Environ Health 2011;10:42.

39 Anderson CA, Zhu G, Falchi M, et al. A genome-wide linkage scan for age at menarche in three populations of European descent. J Clin Endocrinol Metab 2008:93:3965-70.

40 Coyne MD, Kesick CM, Doherty TJ, et al. Circadian rhythm changes in core temperature over the menstrual cycle: method for noninvasive monitoring. Am J Physiol Regul Integr Comp Physiol 2000;279:R1316-20.

41 Meehl GA, Tebaldi C. More intense, more frequent, and longer lasting heat waves in the 21st century. Science 2004;305:994-7.

42 Huang C, Barnett AG, Wang X, et al. Effects of extreme temperatures on years of life lost for cardiovascular deaths: a time series study in Brisbane, Australia. Circ Cardiovasc Qual Outcomes 2012:5:609-14. 


\section{OEM}

\section{Extreme temperatures and emergency department admissions for childhood asthma in Brisbane, Australia}

Zhiwei Xu, Cunrui Huang, Wenbiao Hu, et al.

Occup Environ Med 2013 70: 730-735 originally published online July 24,2013

doi: 10.1136/oemed-2013-101538

Updated information and services can be found at:

http://oem.bmj.com/content/70/10/730.full.html

\section{These include:}

References This article cites 39 articles, 5 of which can be accessed free at: http://oem.bmj.com/content/70/10/730.full.html\#ref-list-1

Email alerting Receive free email alerts when new articles cite this article. Sign up in service the box at the top right corner of the online article.

Topic Articles on similar topics can be found in the following collections

Collections

Notes

To request permissions go to:

http://group.bmj.com/group/rights-licensing/permissions

To order reprints go to:

http://journals.bmj.com/cgi/reprintform

To subscribe to BMJ go to:

http://group.bmj.com/subscribe/ 